\title{
BEHAVIOR OF SALMONELLA HEIDELBERG AND SALMONELLA ENTERITIDIS STRAINS FOLLOWING BROILER CHICK INOCULATION: EVALUATION OF CECAL MORPHOMETRY, LIVER AND CECUM BACTERIAL COUNTS AND FECAL EXCRETION PATTERNS.
}

\author{
Anderlise Borsoi ${ }^{1 *}$, Luciana Ruschel do Santos ${ }^{3}$, Laura Beatriz Rodrigues ${ }^{3}$, Hamilton Luiz de Souza Moraes ${ }^{2}$, Carlos \\ Tadeu Pippi Salle ${ }^{2}$, Vladimir Pinheiro do Nascimento ${ }^{2}$
}

\begin{abstract}
${ }^{1}$ Universidade Tuiuti do Paraná, Faculdade de Medicina Veterinária, Curitiba, PR, Brasil; Centro de Diagnóstico e Pesquisa em Patologia Aviária, Faculdade de Medicina Veterinária, Universaidade Federal do Rio Grande do Sul, Porto Alegre, RS, Brasil; ${ }^{3}$ Faculdade de Agronomia e Medicina Veterinária, Universidade de Passo Fundo, Passo Fundo, RS, Brasil.
\end{abstract}

\begin{abstract}
Over the years, Salmonella Heidelberg (SH) has gained prominence in North America poultry production and in the poultry production of other countries. Salmonella Heidelberg has been isolated and reported from poultry and poultry products in Brazil since 1962, whereas Salmonella Enteritidis (SE) has only emerged as a serious problem in poultry and public health since 1993. These strains of Salmonella can cause intestinal problems in newly hatched chicks, and infection may persist until adulthood. Upon slaughter of chickens, Salmonella can contaminate carcasses, a condition that poses a threat to human health. The aim of this study was to compare the fecal excretion of Salmonella Enteritidis and Salmonella Heidelberg in newly hatched chicks (orally inoculated with $10^{5} \mathrm{ufc} / \mathrm{mL}$ each) until 20 days of age. In addition, the ratio of cecal villus height:crypt depth (morphometry) and liver and cecum cell counts was analyzed in chicks ranging from 0 to 3 days of age and infected with these two Salmonella strains. One hundred seventeen chicks were separated into one of three experimental groups: a control group, an SEinfected group and an SH-infected group. Eight chicks per group were euthanized at 6, 12 and 72 hours post-inoculation (pi) to allow for Salmonella isolation from the liver and cecum and for the collection of the cecum for villi and crypt analysis. Other birds were allowed to mature to 20 days of age and cloacal swabs were taken at 2, 6, 13 and 20 days pi to compare the fecal excretion of inoculated strains. The Salmonella Enteritidis group had a higher number of cells excreted during the trial. Both strains were isolated from the liver and cecum by $6 \mathrm{~h}$ pi. At $12 \mathrm{~h}$ pi the Salmonella Heidelberg group had high cell counts in the cecum. No difference was found in liver cell counts. Both strains showed lower villus height:crypt depth ratio than the control group post-infection.
\end{abstract}

Key words: Salmonella Heidelberg, Salmonella Enteritidis, Fecal Excretion, villus: crypt ratio, Broiler

*Corresponding Author. Mailing address: Secretaria da Coordenação - Veterinária. Rua Sydnei Rangel dos Santos, 238 Santo Inácio, Curitiba, Paraná, Brazil. Postal code 82010-330; Tel.: +55 (41) 3331 7868.; E-mail: anderliseb@ yahoo.com.br 


\section{INTRODUCTION}

Many strains of Salmonella are zoonotic agents, infecting humans through contaminated animal origin food products. In humans, salmonellosis is one of the most common causes of food poisoning. The most common serovars causing disease in humans are Salmonella Enteritidis and Salmonella Typhimurium. In recent years, Salmonella Heidelberg has gained prominence in North America and has also been found in the poultry production of other countries. Salmonella is commercially important in laying hens, turkeys and broiler chickens because of increase in meat and eggs production (3, 9, 20). Salmonella Heidelberg has been isolated and reported from poultry and poultry products in Brazil since 1962 (14), while Salmonella Enteritidis emerged as a serious problem in poultry and public health in 1993. The growth of the Brazilian poultry industry in the 1990's and the increasing number of birds reared in high density environments has created favorable conditions for the maintenance of Salmonella positive flocks (24). The control of Salmonellae in Brazil is regulated by the Poultry National Health Plan developed by the Ministry of Agriculture, Livestock and Food Supply. In 2003, a vaccination for broiler breeders using killed vaccine against Salmonella Enteritidis was approved (23). Some authors have suggested that the presence of one serovar in a flock will reduce the accumulation of others; e.g., such as the situation with the reduction of Gallinarum and the increase of Enteritidis, or the increased presence of Enteritidis displacing other serovars (24). In broiler production, when cecal tonsil colonization is established by Salmonellae bacteria are consistently excreted in the feces (1). Salmonella Heidelberg is present in Brazilian broiler flocks and in an effort to better understand the behavior of this strain, this study was performed to compare the intestinal and liver presence of Salmonella Heidelberg and ATCC Salmonella Enteritidis strains following chick inoculation.

\section{MATERIALS AND METHODS}

Chicks: Recently hatched commercial Ross chicks were obtained from a Brazilian poultry company. All chicks were Salmonella free, hatched from breeders, unvaccinated against Salmonellae and were housed in battery cages. All cages were placed in the same room in three different sectors, and management of the sectors was performed separately to avoid cross-contamination. Water and feed free from antibiotics and animal protein were given ad libitum, and the environmental temperature was set to ensure chick physiological comfort.

Bacteria: Salmonella Heidelberg ( $\mathrm{SH}$ ) was isolated from broiler carcasses in Southern, and Salmonella Enteritidis (SE) ATCC (American Type Culture Collection) 1980 was kindly provided by Dr. Paul Barrow (AFRC Institute for Animal Health, Berkshire, UK). The organisms were retrieved from frozen culture stocks and cultured overnight at $37^{\circ} \mathrm{C}$ in brain heart infusion broth (BHI; Merck, Germany). The culture was streaked on xylose lysine deoxycholate agar (XLD, Difco, UK) and incubated at $37^{\circ} \mathrm{C}$ for 24 hours. Five colony forming units (CFU) of each strain were selected and transferred to BHI and incubated at $37^{\circ} \mathrm{C}$ for 24 hours. CFU was determined by tenfold dilutions in $0.1 \%$ buffered peptone water (BPW, Oxoid, UK) and streaked on XLD agar. The suspension with $10^{5}$ $\mathrm{CFU} / \mathrm{mL}$ was selected for inoculation.

Experimental design: One hundred seventeen chicks were separated into three groups designated as Control, SE and $\mathrm{SH}$. Two groups were inoculated orally with $1 \mathrm{~mL}$ containing $10^{5} \mathrm{CFU} / \mathrm{mL}$ of $\mathrm{SE}$ and $\mathrm{SH}$, and another group was inoculated with saline solution as a control. From each group during the trial, 24 birds were killed, and 15 were kept for Salmonella fecal excretion analysis. All birds were individually numbered by a metal ring placed on the wing. Eight chicks per group were killed by cervical dislocation at 6, 12 and 72 hours postinoculation (pi). At necropsy, the cecum and the liver were collected for Salmonella bacteriological enumeration. Ceca were collected 3 centimeters away from the colon and taken for histological examination and submission for electron microscopy analysis. Cloacal swabs of 15 birds from each group were collected for bacteriological examination at 2, 6, 13 and 20 days pi. At necropsy (21 days pi), cecum and liver were collected for bacteriological examination. The trial was 
approved and performed according to the recommendations of the Faculty Ethics Committee of Veterinary Medicine, Federal University of Paraná, Brazil.

Bacterial identification in chick liver and cecum: Two pools of four birds per group had their organs homogenized in $2 \% \mathrm{BPW}$ (ten times the volume of organs by weight). BPW cultures were diluted tenfold in BPW up until a dilution of $10^{-3}$, followed by streaking in duplicate on XLD agar plates, incubation for 24 hours at $37^{\circ} \mathrm{C}$ and $\mathrm{CFU}$ counting, adapted from Desmidt et al. (6). All organ samples were also incubated for $16-18$ hours at $37^{\circ} \mathrm{C}$, and $100 \mu \mathrm{L}$ from each $\mathrm{BPW}$ were inoculated in $10 \mathrm{~mL}$ of Rappaport Vassiliadis (RV; Merck, Germany) and placed at $42^{\circ} \mathrm{C}$ for 24 hours. The RV samples were streaked on XLD agar (24 hours at $\left.37^{\circ} \mathrm{C}\right)$. Salmonella CFU were counted and the results expressed according to the Plate Count Proceedings recommended by Normative Instruction $\mathrm{N}^{\mathrm{o}} 6$ from the Brazilian Ministry of Livestock and Food Supply (18). One typical colony per plate was biochemically and antigenically screened to confirm Salmonella identity.

Bacteriological examination for cloacal swabs: Some cloacal swabs were directly inoculated on XLD agar, and others were placed in $2 \mathrm{~mL}$ of $2 \%$ BPW. BPW cultures were diluted tenfold in BPW until a dilution of $10^{-3}$ was reached, and $100 \mu \mathrm{L}$ of the diluted suspension was plated out in duplicate on XLD agar, adapted from Desmidt et al. (6). Salmonella colonies were counted, and the results were expressed according to the Plate Count Proceedings recommended by Normative Instruction $\mathrm{N}^{\circ} 62$ published August 26, 2003 and recommended by the Brazilian Ministry of Agriculture, Livestock and Food Supply (18). One typical colony per plate was biochemically and antigenically screened to confirm the presence of Salmonella. From the initial dilutions, $100 \mu \mathrm{L}$ were enriched in $10 \mathrm{~mL}$ of Rappaport Vassiliadis (Merck, Germany), incubated at $42^{\circ} \mathrm{C}$ for 24 hours and plated on XLD agar. The threshold of Salmonella detection after direct plating was 10 $\mathrm{CFU} / \mathrm{mL}$. Samples that were negative after direct plating but positive for Salmonella after enrichment were presumed to contain less than $10 \mathrm{CFU} / \mathrm{mL}$ and were given a value of 0.699 $\log _{10}$ during statistical analysis. Samples that were negative after direct plating were presumed to contain $0 \mathrm{CFU} / \mathrm{mL}$. Regarding cecum and liver samples collected at necropsy (21 day old chickens), 25 grams of each organ was added to 225 $\mathrm{mL}$ of BPW in sterile plastic bags and homogenized for 2 minutes. The procedures for counting or isolation were the same as described above.

\section{Histological examination and villus and crypt analysis:} Cecum samples were fixed in $4 \%$ phosphate-buffered formaldehyde, paraffin-embedded, sectioned at $5 \mu \mathrm{m}$ and stained with hematoxylin and eosin (HE). The cecum samples processed for histological examination were measured for villi height and crypt depth. These data were taken from the tip of the villus to the valley between individual villi, and measurements for crypt depth were taken from the valley between individual villi to the baso-lateral membrane (Thompson, Applegate, 2006). Villi and crypts (50 of each) were measured for each time per group (21). The villus and crypt study was carried out using an image-analyzing system (Motic Images Plus 2.0-Motic China Group Co.2006), coupled to a microscope (Olympus BX41 Olympus America INC., NY, USA).

Electron microscopy: Cecum sections were collected to perform scanning photomicroscopy analysis. These sections were processed as described by Maiorka et al. (17).

Statistical analysis: Data were submitted for analysis of variance using StatView SAS software (1992-98-SAS Institute Inc. USA) and means were compared using the Tukey test at a $5 \%$ significance level $(\mathrm{P}<0,05)$.

\section{RESULTS}

Salmonella isolation and villi height:crypt depth analysis. Quantification of Salmonella per gram of cecum and liver and the relationship between villi height and crypt depth were analyzed for 72 hours pi with two different Salmonella strains, serovars Enteritidis (SE) and Heidelberg (SH). The control group was not infected with Salmonella. At 6 hours pi, the two strains were present in the cecum and liver. SH had a higher $\mathrm{CFU} / \mathrm{g}$ count in the cecum at 12 hours pi than did SE, but no 
difference was observed in number of cells in the liver between the two strains (Table 1). For the villus height:crypt depth ratio,

the SE and SH groups were significantly different from the control group (Table 2).

Table 1. Bacteriological counting of Salmonella (S) Heidelberg and Salmonella Enteritidis per gram of caeca and liver tissue from newly hatched chicks inoculated with $10^{5} \mathrm{CFU} / \mathrm{mL}$. Data are the means of organs collected from eight animals at each time point.

\begin{tabular}{lllllll}
\hline $\begin{array}{l}\text { Time post - } \\
\text { inoculation }\end{array}$ & Control cecum & $\begin{array}{l}\text { S. Enteritidis } \\
\text { cecum }\end{array}$ & $\begin{array}{l}\text { S. Heidelberg } \\
\text { cecum }\end{array}$ & $\begin{array}{l}\text { Control } \\
\text { liver }\end{array}$ & $\begin{array}{l}\text { S. Enteritidis } \\
\text { liver }\end{array}$ & $\begin{array}{l}\text { S. Heidelberg } \\
\text { liver }\end{array}$ \\
\cline { 2 - 6 } & CFU/g & CFU/g $\log _{\mathbf{1 0}}$ & CFU/g $\log _{10}$ & CFU/g & CFU/g $\log _{10}$ & CFU/g log 10 \\
\hline $0 \mathrm{~h}$ & - & - & - & - & - & - \\
$6 \mathrm{~h}$ & - & $3.22 \pm 2.16$ & $3.11 \pm 2.32$ & - & $2.20 \pm 2.12$ & $2.69 \pm 2.81$ \\
$12 \mathrm{~h}$ & - & $3.99 \pm 0.06^{\mathrm{b}^{*}}$ & $4.70 \pm 0.03^{\mathrm{a}}$ & - & $0.69 \pm 0.00$ & $0.69 \pm 0.00$ \\
$72 \mathrm{~h}$ & - & $4.10 \pm 0.64$ & $4.37 \pm 0.36$ & - & $1.74 \pm 0.29$ & $1.08 \pm 0.55$ \\
\hline
\end{tabular}

CFU/g: Colony Forming Units per gram. Original counts transformed into $\log _{10}$.

*Different letters in the same line denote means that are significantly different according to a Tukey test at a $95 \%$ level of confidence $(\mathrm{p}<0.05)$.

Table 2. Cecal villus height:crypt depth ratio $(\mu \mathrm{m})$ measurements from cecal samples of chicks inoculated with Salmonella $(S)$ Heidelberg and Salmonella Enteritidis at different time points post-inoculation.

\begin{tabular}{llcc}
\hline Time post-inoculation & Control & $\begin{array}{l}\text { S. Enteritidis } \\
\text { Villus:crypt }\end{array}$ & $\begin{array}{l}\text { S. Heidelberg } \\
\text { Villus:crypt }\end{array}$ \\
\hline $6 \mathrm{~h}$ & ${ }^{*} 5.21 \pm 2.28$ & ${ }^{\mathrm{b}} 4.49 \pm 1.62$ & ${ }^{\mathrm{b}} 5.09 \pm 1.56$ \\
$12 \mathrm{~h}$ & ${ }^{\mathrm{a}} 6.59 \pm 9.44$ & ${ }^{\mathrm{b}} 4.28 \pm 1.10$ & ${ }^{\mathrm{b}} 5.21 \pm 1.87$ \\
$72 \mathrm{~h}$ & ${ }^{\mathrm{a}} 7.62 \pm 2.36$ & ${ }^{\mathrm{b}} 5.63 \pm 1.89$ & ${ }^{\mathrm{a}} 7.14 \pm 2.20$ \\
\hline
\end{tabular}

\section{Salmonella Enteritidis and Salmonella Heidelberg}

Fecal Excretion: The SH strain at 2 days pi showed a higher cell count than the SE strain, which could only be counted after selective enrichment. At 6 days pi, the strains showed no difference in the number of cells excreted in the cloacal swabs. 6 days pi, the SE strain showed higher levels of excretion than the SH strain (Table 3 and Figure 4). From the direct agar plate (DAP), it was possible to determine that the SH group had a high number of positive birds at 2 days pi, whereas the $\mathrm{SH}$ positive birds showed a gradual increase in total numbers according to the DAP. Due to the individual identification of birds in the groups, it was possible to observe that all birds were positive for Salmonella at some point during the experiment. At the necropsy performed 21 days pi, all birds were found to be positive for SH or SE in the liver, while the cecum bacterial counts were higher in the SH group than in the SE group. Means and standard deviation to bacterial counts into the cecum were $1.34 \pm 1.37$ for $\mathrm{SE}$ and $2.96 \pm 1.52$ for $\mathrm{SH}$, with $\mathrm{p}<0.05$ between the two groups. Data obtained from analyses of the cecal contents did not correlate with the results from the last cloacal swab taken one day before euthanasia.

Electron microscopy: Figure 1 shows the cecum scanning photomicroscopy of birds from the control group, and some injured areas are apparent. Figures 2 and 3 from birds infected with Salmonella Heidelberg $\left(10^{5} \mathrm{CFU} / \mathrm{mL}\right)$ show villi with aspects of edema, rough aspect, mucosal erosion, degenerate cells and attached bacteria. 
Table 3. Percentage of positive samples in direct agar plating (DAP) and fecal excretion counting of Salmonella Enteritidis (SE) and Heidelberg $(\mathrm{SH})\left(10^{5} \mathrm{CFU} / \mathrm{mL}\right)$. Original number transformed in $\log _{10}$.

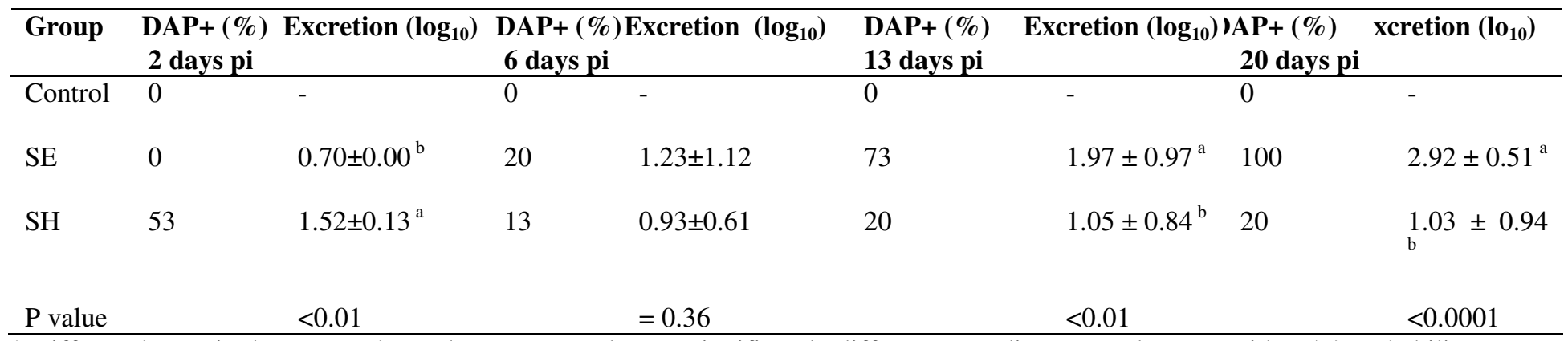

* Different letters in the same column denote means that are significantly different according to a Tukey test with a $5 \%$ probability of error $(\mathrm{p}<0.05)$. pi: post-inoculation; DAP +: direct agar plating positive; pi: post-inoculation.
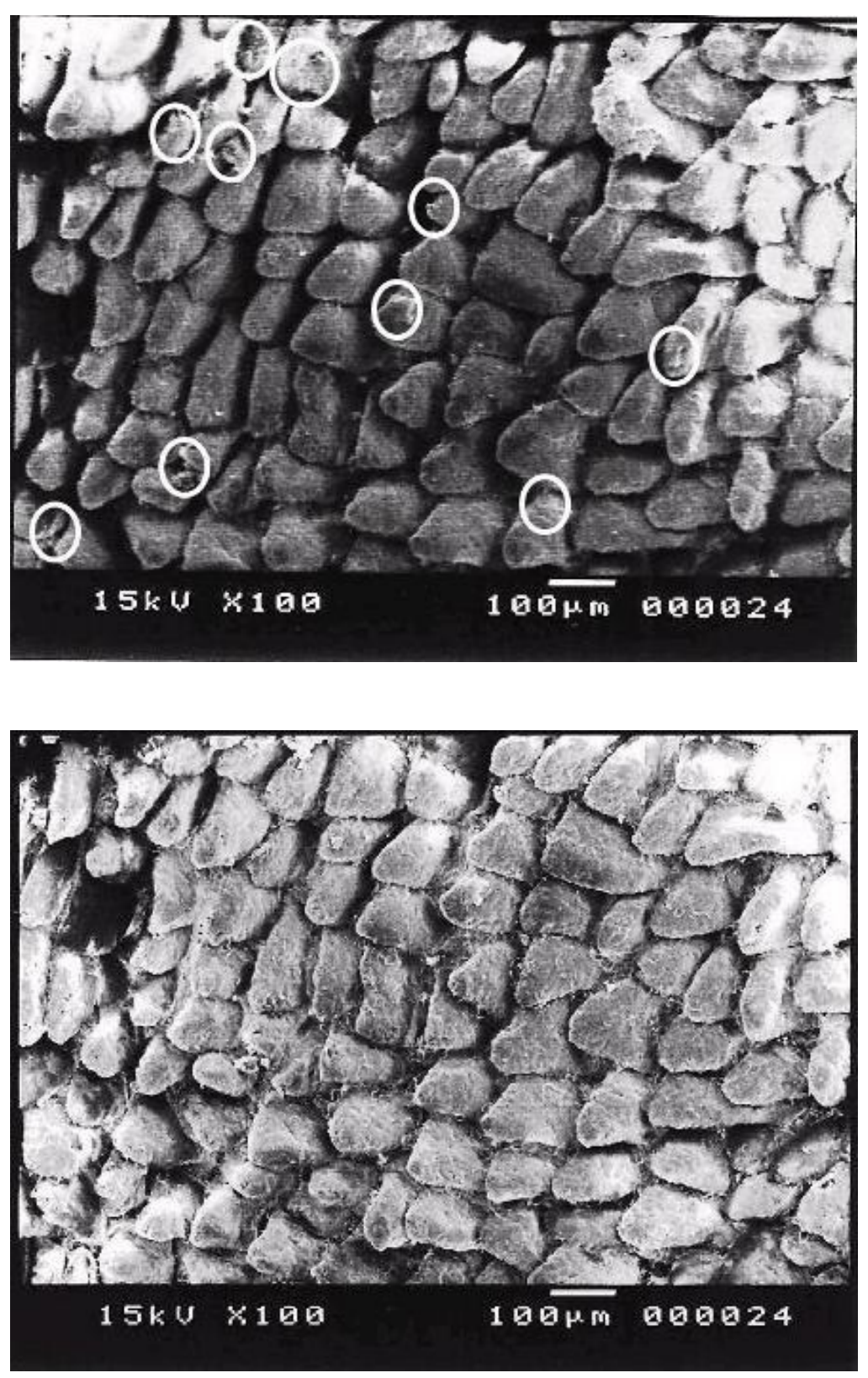

Figure 1. Electron microphotograph of the cecum of chicks from the Control group, 3 days post-inoculation with a saline solution (X100). In the circles, the apical region of some villi with injured areas.

Figure 2. Electron microphotograph of the cecum of a chick at 3 days post-inoculation with $10^{5} \mathrm{CFU} / \mathrm{mL}$ of $S$. Heidelberg (X100). Villi have an aspect of edema and surfaces with rough aspect or mucosal erosion. Space between the villi shows structures similar to bacilli and cellular debris. 

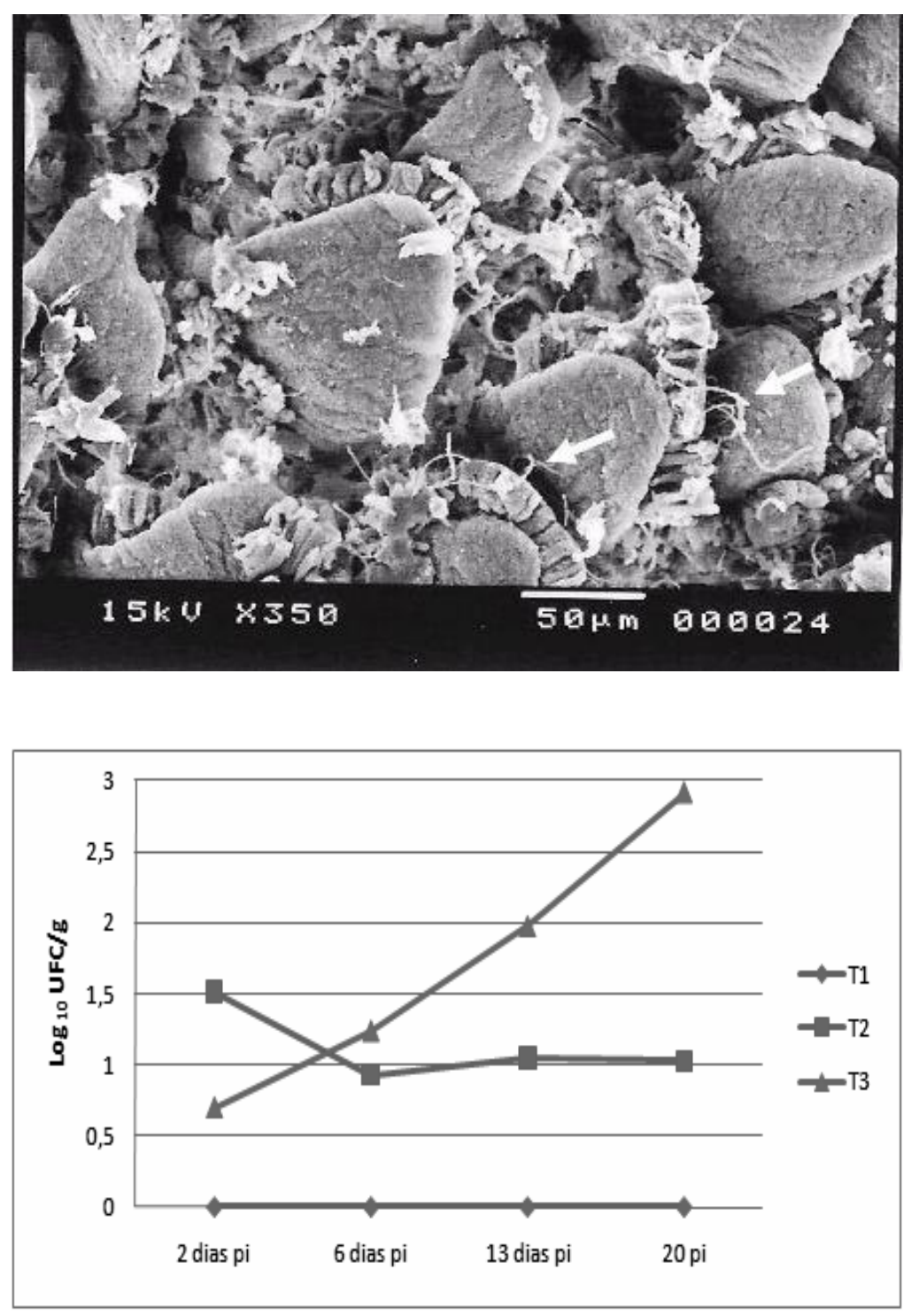

Figure 3. Electron microphotograph of the cecum of chicks at 3 days post-inoculation with $10^{5} \mathrm{CFU} / \mathrm{mL}$ of $S$. Heidelberg (X350). Attached bacteria (arrows) in epithelial cells and between the villi can be detected. Structures similar to bacilli and compatible with cellular debris or groats of bacteria present.

Figure 4. Salmonella Enteritidis and Salmonella Heidelberg fecal excretion from 2 to 20 days postinoculation. T1: saline inoculation, T2: Salmonella Heidelberg and T3: Salmonella Enteritidis ATCC.

\section{DISCUSSION}

Previous studies performed with Salmonella Enteritidis in different broiler lines have demonstrated an inverse relationship between the severity of cecal infection and the colonization of systemic organs in animals of similar ages and challenge $(16,22)$. In the present study, we also found cell counts from the cecum to be higher than in the liver for chicks infected with SE and SH (Table 1). The different cecum and liver colonization levels may be due to Salmonella colonization virulence systems that are based on two Salmonella pathogenic island systems (SPI 1 and 2) responsible for intestinal (SPI 1) and systemic (SPI 2) host infection. The expression of these island systems are regulated in response to different environmental factors. For example, SPI 1 responds to low oxygen levels and high osmolarity in the gut lumen, whereas SPI 2 responds to low magnesium and phosphorus levels inside host cells (4).

According to Nabburs (19), under optimal circumstances, intestinal villi should be high and crypts should be shallow, resulting in a high villus height to crypt depth ratio. In the present work, from 0 to 3 days pi, SE and SH groups had low villus height:crypt depth ratios when compared to the control group, possibly because of SE and SH damage caused to the 
intestinal mucosa. Reductions in the villi height:crypt depth ratios can occur due to intestinal pathogen infection and are seen under other certain conditions in poultry, including after feed withdrawal (25) and in response to some feed additives that are used during growout $(12,8,21)$. These changes have been attributed to reduced cell migration and proliferation rates, along with increased rates of cell loss and programmed cell death (7).

Intestinal mucosa alterations found in this work may have occurred because immediately after hatching, chicks have an immature immune system, and the protection of intestinal mucosa depends on barrier cells (macrophages, natural killer cells, heterophils), chemical and physical factors, and the presence of Paneth cells. Paneth cells are located in the crypt and secrete defensins and phospholipase that lyses bacteria, fungi and enveloped viruses (15).

Infection of newly hatched chicks with Salmonella Enteritidis by oral inoculation or by horizontal contact exposure can lead to the establishment of intestinal colonization that persists into adulthood (10) because of the ability of this pathogen to replicate inside host cells, most prominently in phagocytic cells such as macrophages (13). In our study, SE and SH strains were inoculated in chicks, and cloacal swabs were taken until 20 days of age. As with previous trials utilizing these two strains (2), the birds infected with SE excreted a very low Salmonellae number at 2 days pi (Table 3).

Initially, the SH group had the highest bacterial counts from the cloacal swabs, but this number decreased over time until 20 days pi. In contrast, birds with SE showed an increase in the number of positive birds and cell counts throughout the trial. Table 3 shows a comparison between isolation in direct agar plates (DAP) and the number of cells at each time point, showing that the number of birds DAP positive in the SE group increased along with the number of cells isolated. From the measurements, it could be determine that when the excretion level per bird was above $10 \mathrm{CFU} / \mathrm{mL}$, it was detectable in DAP. When individual birds were identified it was also determined that all birds were positive at a minimum of one time point analyzed and often the same bird was positive for more than one time point.

Scanning photomicroscopy showed that the apical region of some villi was affected in the control group, which can be ascribed to natural cell turnover (Figure 1). Figures 2 and 3 show the changes in the intestinal villi of the $\mathrm{SH}$ group. Aspects of edema, rough surface, mucosal erosion, epithelial cell degeneration, and the presence of cellular debris in the space between villi were suggested by scanning photomicroscopy. These results are in agreement with Desmidt et al. (5), who observed adhesion and colonization of Salmonella in the cecal lumen.

The importance of Salmonella Enteritidis is well established in the poultry industry and human health. Similarly, in the last few years, the presence of Salmonella Heidelberg in laying hens producing contaminated eggs $(7,8,9,26)$ and as a cause of human illness (3) has been documented. The present work demonstrates that changes in the intestinal mucosa caused by Salmonella Heidelberg are similar to those caused by Salmonella Enteritidis; specifically, Salmonella is present in the liver of newly hatched chicks and persists in the fecal excretion of broiler chickens. These findings suggest that Salmonella Heidelberg may have importance as a pathogen to newly hatched chicks and is a potential broiler carcass contaminant.

\section{ACKNOWLEDGEMENTS}

The authors thank the professionals at the Center for Diagnostics and Research in Avian Pathology (UFRGS), the professionals at the Laboratory of Microbiology and Avian Pathology (UFPR), and Da Granja Poultry Company for the chicks. This study was supported by the Brazilian National Council of Research $(\mathrm{CNPq})$ and the Coordination for the Improvement of Higher Education Personnel (CAPES).

\section{REFERENCES}

1. Backer, R.C.; Golf, J.P.; Mulnix, E.J. (1980) .Salmonellae recovery following oral and intravenous inoculation of laying hens. Poult. Sci. 
v.59, p. 1067-1072.

2. Borsoi, A; Santin, E.; Diniz, G.S.; Nascimento, V.P. (2008). Excreção de Salmonella Eneritidis e Heidelberg Inoculadas em Pintinhos de Corte e Avaliada por Suabe de Cloaca. Rev. Bras. Cienc. Avíc. v.10, p. 232-232.

3. Chittick, P.; Sulka, A.; Tauxe, R.V.; Fry, A.M.A. (2006). Summary of National Reports of foodborne outbreaks of salmonella Heidelberg infections in the United States: clues for disease prevention. J. Food Prot. v.69, n.5, p.1150-1153.

4. Deiwick, J.; Nikolaus, T.; Erdogan S.; Hensel M. (1999). Environmental regulation of Salmonella Pathogenicity Island 2 gene expression. Mol. Microbiol. v.31, p.1759-1764. 1999.

5. Desmidt, M.; Ducatelle, R.; Haesebrouck, F. (1998a). Immunohistochemical observations in the ceca of chickens infected with Salmonella Enteritidis phage type four. Poult Sci. v.77, p.73-74.

6. Desmidt, M; Ducatelle, R.; Haesebrouck, F. (1998b) Serological and bacteriological observations on experimental infection with Salmonella Hadar in chickens. Vet. Microbiol. v.60, p.259-269.

7. Ferraris, R.P.; Carey, H.V. (2000). Intestinal transport during fasting and malnutrition. Ann. Rev. Nutr. v.20, p.195-219.

8. Friesen, K.G.; Goodband, R.D.; Nelssen, J.L.; Blecha, F.; Reddy, D.N.; Reddy, P.G.; Kats, L.J. (1993). The effect of pre- and postweaning exposure to soybean meal on growth performance and on the immune response in the early-weaned pig. J. Anim. Sci. v.71, p.2089-2098, 1993.

9. Gast, R.; Guard-Bouldin J.; Holt, P.S. (2004). Colonization of reproductive organs and internal contamination of eggs after experimental infection of laying hens with Salmonella Heidelberg or Salmonella Enteritidis. Avian Dis. v.48, p. 863-869.

10. Gast, R.; Guard-Bouldin J.; Holt, P.S. (2005). The relationship between the duration of fecal excretion and the production of contaminated eggs by laying hens infected with strain Salmonella Enteritidis and Salmonella Heidelberg. Avian Dis. v.49, p. 382-386.

11. Gast, R.; Guraya, R.; Guard-Bouldin J.; Holt, P.S.; Moore, P.S. (2007). Colonization of specific regions of the reproductive tract and deposition at different locations inside eggs laid by hens infected with Salmonella Enteritidis or Salmonella Heidelberg. Avian Dis. p.40-44.

12. Hancock, J.D.; Peo, E.R. JR.; Lewis, A.J; Moxley. P.A. (1990). Effects of ethanol extraction and heat treatment of soybean flakes on function and morphology of pig intestine. J. Anim. Sci. v.68, p.3244-3251.

13. Hansen-Wester, I.; Hensel, M. (2001). Salmonella pathogenicity islands encoding type III secretion systems. Microb Infect, v.3, p.549-559.

14. Hofer, E.; FIlho, S.J.S.; Reis, E.M.F. (1997). Prevalência de sorovares de Salmonella isolados de aves no Brasil. Pesq. Vet. Bras. p.55-62.

15. Ito, N.M.K.; Miyaji, C.L.; Okabayashi, S.M. (2007). Saúde intestinal em frangos de corte. Circular Técnica Aviagen do Brasil. URL<http:// www. agroceresross.com.br/images/noticias/384CircularTecnicaAviagen_2007 11.pdf>. 2007.

16. Kramer, J.; Visscher, A.H.; Wagenaar, A.G.; Boontra-Blom, A.G.; Jeurissen, S.H.M. (2001). Characterization of the innate and adaptive immunity to Salmonella enterica serovar Enteritidis PT1 infection in four broiler lines. Vet. Immunol. Immunopat. v.79, p.219-233.

17. Maiorka, A.; Santin, E.; Dahlke, F.; Boleli, I.C.; Furlan, R.L.; Macari, M. (2003). Post hatching water and feed deprivation affect the gastrointestinal tract and intestinal mucosa development of broiler chicks. J. Appl. Poult. Res. v.12, p.483-492.

18. MAPA (Ministério da Agricultura, Abastecimento e Pecuária). 2003. Diário Oficial da União. Instrução Normativa, SDA No 62, de 26 de agosto de 2003.

19. Nabburs, M.J. (1995). Microbiological, structural and functional changes of the small intestine of pigs at weaning. Pig News Inform. v.16, n.3, p.93-97.

20. Nayak R.; Kenney, P.B. (2002). Screening of Salmonella isolates from a turkey production facility for antibiotic resistance. Poult. Sci. v.81, p.1496-1500.

21. Pelicano, E.R.L.; Souza, P.A.; Souza, H.B.A.; Figueiredo, D.F.; Amaral, C.M.C. (2007). Morphometry and ultra-structure of the intestinal mucosa of broilers fed different additives. Braz. J. Poult.Sci. v.9, n.3, p.173-180.

22. Sadeyen, J.R.; Trotereau, J.; Velge, P.; Marly, J.; Beaumont, C.; Barrow, P.A.; Bumstead, N.; Lalmanach, A.C. (2004). Salmonella carrier state in chicken: comparison of expression of immune response genes between susceptible and resistant animals. Microb. Infect. p.1278-1286.

23. SDA. (2003). Instrução Normativa $n^{\circ}$ 78. Aprova as Normas Técnicas para Controle e Certificação de Núcleos e Estabelecimentos Avícolas, como livres de Salmonella gallinarum e de Salmonella pullorum e livres ou controlados para Salmonella enteritidis e Salmonella typhimurium. Secretaria de DefesaAnimal. URL <http://www.agricultura.gov.br /portal/page?_pageid=33,981919\&_dad=portal\&_schema=PORTAL $>$. 2003.

24. Silva, E.N.; Duarte, A. (2002). Salmonella Enteritidis em aves: retrospectiva no Brasil. Rev. Bras. Ciênc. Avic. v.4, n.2, p.85-100.

25. Thompson, K.L.; Applegate, T.J. (2006). Feed withdrawal alters smallintestinal morphology and mucus of broiler. Poult. Sci. v.85, p.15351540.

26. Zancan, F.T.; Berchieri Jr, A.; Fernandes, S.; Gama, N.M.S.Q.(2000) Salmonella spp investigation in transport boxes of day-old birds. Braz. J. Microbiol. v.31, n.3, p. 229-23. 